\title{
Decoding the Disciplines in higher education institutions
}

\section{Chistolini, Sandra}

Department of Education, Università degli Studi Roma Tre, Italy

\begin{abstract}
Decoding the Disciplines is a methodology aimed to support teachers and students of University to tackle obstacles and difficulties in learning process. It is assumed that students come to classroom with different level of secondary school preparation and teachers are generally reinforcing the inequalities in principle deplored as form of injustice in our society. The question of giving tools that students need to succeed in our disciplines requires new strategies intend to make teaching effective in line with the development of the democratic vision of teaching. The methodology represents a dynamic sequence of steps based on the understanding of the content of discipline taught and learned. All disciplines are involved, humanities as well as sciences. Under the Erasmus Plus Programme some European Universities are collecting relevant evidences to understand what to teach about an academic discipline. Monitoring students' learning and motivation means to bring out the bottlenecks, which hinder the achievement of knowledge and slow down the learning process leading to failure. Presentation of initial results aims to share the benefits of this methodology able to guide students to master basic mental operations required in university courses. Decoding emerges as challenge and option for policymakers of higher education.
\end{abstract}

Keywords: Decoding the Disciplines; student learning; university teaching; democracy; scientific knowledge. 


\section{Introduction}

The university preparation of teachers, who will work in schools and must needs be competent in the discipline of teaching, requires a forma mentis that is flexible enough to be able to combine knowledge and strategies, depending on the needs and expectations that are changing so quickly. To acquire and convert knowledge to make studying attractive, impassion research and encourage new ideas constitute the distinctive corollaries of each educational process intended to promote cultural progress and economic development.

The close relationship between knowledge heritage and improvement of living conditions infers concrete commitment, from the political and social implications so that university teaching is adjusted to the widespread idea of triangular growth, in terms of intelligence, sustainability and inclusion, as present in the European recommendations and having become a permanent scope in evaluating best practices.

To add more vitality to university teaching means actively accompanying the students in the aware assumption of their responsibilities towards mastery learning. To know how to study, internalise, interpret and create solutions requires the capacity to relate to the teacher, with whom a profitable, learning dialogue has been established, that is, conversing in such a way that the lesson transforms into an existential project, in which to believe and to which one commits oneself.

This interactive teaching model can be realised in differentiated learning environments, in which both humanistic and digital technologies are used.

Humanistic perspective, meaning human contact between teacher and learner, allowed students to express their difficulties in what is object of knowledge during learning process concerning specific discipline. In fact, this attitude requires more attention to educational relationships and a cure of the single section of the process. The profile of teacher is focused on the ability of bringing into light bottlenecks, obstacles, encountered by the students in the classroom.

Mathematics uses humanistic technologies, when it sets up a significant educational relationship that results in successful preparation. There are relevant studies about the human factor in economics, in which the order of the addendums is reversed. This restores vitality and responsibility to persons, placing them in the top position, while monetary earnings are recognised as the engine of change depending on the acting person. From this perspective the studies of Levinas (1985), Burggraeve (1997), De Simone (2001), Sen (2011), Zamagni (2012) are very important in considering the relevance of human person in economics.

Digital; meaning with the aid of on-line communication as an indispensable opportunity at all levels of learning, and as a guaranteed access tool to information. 
The international comparison on these subjects allowed for the participation in the Erasmus+ project on the methodology known as Decoding the Disciplines and its subsequent application to various university courses, specifically the course of general Pedagogy and the Mathematics course. For purposes of recognition herein, reference will mainly be made to the proposal concerning the course of general Pedagogy, basic annual teaching in the degree course in Primary Education Sciences.

Being emphasised in this paper are the salient aspects of European cooperation for developing superior systems of instruction and training. Decoding the Disciplines is interpreted as the key to a preferred path to cut down on university drop-outs, by acting on the methods for accessing knowledge, until a sizable rise in active participation and success of the students is enabled, starting from the first year of university studies.

\section{European objectives and ways of reasoning for innovation}

In the Conclusions of the Council on a strategic framework for European cooperation in education and training of 12 May 2009 ( «ET 2020»), we read that “in the period to 2020, the primary goal of European

cooperation should be to support the further development of education and training systems in the Member States which are aimed at ensuring: (a) the personal, social and professional fulfilment of all citizens; (b) sustainable economic prosperity and employability, whilst promoting democratic values, social cohesion, active citizenship, and intercultural dialogue (Council, 2009, p. 3). This is not only a European, but also a worldwide objective, having considered the impact of training on the entire system of planet Earth and the extension of employability on the international market. Young people are prepared to look beyond national borders and choose places of work, in which their competences can be fully recognised. In the period up to 2020 ,

In this regard, Europe 2020 emphasises three interconnected priorities: 1) intelligent growth that means development of an economy based on knowledge and innovation; 2) sustainable growth through the promotion of a more efficient economy from a point of view of resources; 3) inclusive growth intended to promote an economy with an employment rate high enough to support social and territorial cohesion. Three areas of action for achieving these priorities are indicated hereafter (Unità Organizzativa, 2010, pp. 15-28).

The first concerns innovation and refers to European spending for research and development, still at $2 \%$ in 2010 and, thus, below the percentages recorded for the United States $(2.6 \%)$ and Japan (3.4\%); the auspice for Europe is moving in the direction of increasing investments in the private sector and high technology. 
The second area of action is that of education, training and lifelong learning and directs new attention to students with limited reading capacities, youth who leave their studies at an early age, that is, the $50 \%$ who have an average level of qualification that often does not meet the job-market requirement. Of note, on the whole, is that, in Europe, a university degree is obtained by less than one person out of three, at the age of between 25 and 34, whilst in the United States, under the same conditions, this factor is $40 \%$ and $50 \%$ in Japan. The Shanghai Ranking lists two European universities among the top 20 worldwide (Cambridge and Oxford).

The Academic Ranking of World Universities 2016 (The ARWU, 2017) indicates three British universities among the top 20 (Cambridge, Oxford, University College London) and one Swiss university (Swiss Federal Institute of Technology Zurich). In the classification of The Times Higher Education World University Rankings (2017), in the section concerning Young University Rankings 2017, the École Polytechnique Fédérale de Lausanne ranks in first place and the Scuola Superiore Sant'Anna in ninth place, at the same rank as the Karlsruhe Institute of Technology.

The third area of action, towards which Europe is moving is that of the digital society, in consideration of the fact that the global demand for information technology and communications represents a very extensive market, in which the participation of European businesses is still scant, due also to the delay in the use of high-speed internet. The slowness of on-line communication hinders innovation, particularly in rural areas, the spread of knowledge and distribution of goods and services.

\section{From mastery learning to Decoding the Disciplines}

Starting from 1956, Benjamin S. Bloom made contributions concerning the human characteristics of learning. He showed how the lack of scholastic success of students does not depend on their intelligence quota, but rather the capacity of teachers to prepare the discipline for progressive acquisitions, so as to result in the full mastery of the assignment. The implications of Bloom's taxonomic model, according to which teachers are trained to organise their teaching by promptly intervening, if necessary, and not attributing inappropriate responsibilities to the students, have aroused worldwide interest, to the point of generalising this same pedagogic lexicon of teaching by prerequisites, objectives, processes, evaluation and feedback.

The basic idea of the theory of mastery learning, i.e. the progressive mastery of the discipline, can be summed up as the student learning, when confronted with the problem of what is being taught with sensitivity, a good system and clarity (Bloom, 1979, pp. 34-37). Nothing new from this point of view. What is new would be not so much in the identifying 
profile of the teacher, but rather in the assumption by the teacher that the student is able to learn, if the teacher helps the development of the student's capacity to understand. The difficulties are highlighted and the time required for overcoming them, that is, to master them, is established. The revolution of the traditional model is evident. It is perfectly clear how Bloom himself particularly aimed at frequent feedback to follow-up on and correct the learning process. Shifting the attention from the teacher of the subject-matter and the student to the teaching-learning strategy has an immediate impact of reinforcing the motivation of the student and giving suitable support at the right time.

After decades of scientific work on mastery learning, researchers in the United States have continued to pursue the fine-tuning of the original theory. The concentration of critical thought on the subject of study has led to working up the methodology known as Decoding the Disciplines. The attempt to help students learn how to analyse, summarise and assess could meet with obstacles in the building of a higher order of thought, due to the gap created between the degree of thought required in the classroom and the generic assumptions being introduced. To prevent and overcome these difficulties, the relevance in facing the issue within each special field of discipline is emphasised. The general reference structure represents the epistemic, cognitive and emotional framework of the process, completed by the specific, in-depth examination of the discipline. Bloom's mastery learning and collaborators refer mainly to schooling, while the research in Decoding the Disciplines shifts in a parallel manner into higher university education.

According to the reconnaissance of John Middendorf and David Pace (2004, pp. 1-2), we can define a typology of the development of the new methodology in the academic world, starting with the studies of Shulman, Brown, Collins, Duguid, Tobias.

Lee Shulman (1987) sustains that teachers' training must pass from general theoretical proposition to the study of learning in environments created by disciplinary teaching. Other academics (Brown, Collins, Duguid, 1989) talk about "cognitive apprenticeship", as the process of learning academic disciplines compared to learning various functions in a foreign culture. Observations in the field (Tobias, 1992-1993) reveal the difficulties of even expert educators and qualified students, under conditions of transferring into inferior teaching environments, far from their own specific disciplinary competences. This is a clear sign that possessing the discipline requires adjustments to the environment that cannot be given solely in the form of the general theory of learning.

This defines the fundamental epistemological problem that one needs to try to dissect and comprehend on two analytical planes: the plane of theorised knowledge and the plane of the discipline taught. 


\section{The responsibility of activating the learning process}

Researchers, who are interested in studying the nature of the discipline, who teach by monitoring the results of the students, show a great responsibility towards the social and cultural implications of teaching. They truly want to know what remains of what they teach, and the evaluation of the feedback relative to the mastery of the knowledge by the young people is considered an indispensable step towards improving the performance of both parties: teacher and student.

The often unsatisfied comments of the teachers about the way the students give their feedbacks on the contents of the discipline heighten the search for quality of the educational offer. To improve one's own teaching method, one can start from various tracks. No matter what the case, to scientifically study thought and learning, it is necessary to link the disciplinary knowledge to what occurs with the students in the classroom. There are teachers with excellent knowledge, but who are actually unable to communicate the contents of their own discipline and, vice versa, there are teachers who were not considered exceptional as students, but who are masterly experts in getting students to participate in a work plan, through which learning takes place in a natural, spontaneous, easy, painless, interesting and pleasant way. The attraction to the discipline is not only linked to the contents, but requires that bit of curiosity, without which the contents, learned quite rapidly at the time and solely for administrative purposes, are just as quickly forgot. Not a remnant is left in the mind or heart of the student.

Decoding the Disciplines is a process for accessing the way to think and learn within the discipline; a progressive decoding that makes something rise to the surface that is tacitly concealed in the labyrinths of the discipline itself and that is now required to be consciously and responsibly exposed. Each discipline is undoubtedly built on acquisitions promoted for decades and expanded thanks to scientific research. We are now asking students to revisit and make their own, hereby demonstrating not only having understood it, but also having achieved a self-awareness of the understanding.

The research, around which the Erasmus+ project entitled Decoding the Disciplines in European Institutions of Higher Education: Intercultural and Interdisciplinary Approach to Teaching and Learning, is working with the participation of Universities of Belgium (Vives), Italy (Roma Tre), Lithuania (Kaunas and Vilnius) and Ireland (Galway) has been inserted into the history of the model used by Indiana University Faculty Learning Community (IUFLC) (2016-2019) since the second half of the 1980s. 


\section{The ethical issue of social justice}

David Pace (2017, p. xi), one of the most diligent academics in the field of methodology, states having begun tracing the path starting from 1988 and meeting face-to-face with Craig Nelson, deemed the elderly wise man in the world of teaching. This colleague, with the most experience, emphasised how what we usually call teaching is actually a sorting of talent. The proof of success of students with early education and, thus, the lack of success of students with minimum preparation, created two categories. The talented and intelligent were listed on one side and, on the other, were the lazy and non-intelligent ones. By contrast, teaching implies that all students are given the tools, which they require to be successful in the discipline.

The feeling of injustice derived from ineffective teaching describes the situation proven by Pace and, moreover, well-known from analytical, pedagogic literature about the scholastic selection, to which the criticism of university mortality is placed side-by-side. The memory of don Milani and the School of Barbiana, in Italy, is compulsory to this subject. The book Lettera a una professoressa (Letter to a teacher) (1967) contains the charge against a system that reproduces the injustice of exclusion and the classification in talented and not talented, at school and in universities.

In half a century, we have made many advances, but we have not overcome the problem, seeing as how the subject of dropping out continues to be especially relevant in Italy. In the report about monitoring education and training, the European Commission (2015, p. 4) recorded $15.0 \%$ for Italy in 2014 and $11.1 \%$ as a European mean with respect to young people in the age bracket of 18-24 who left their studies or training early.

The responsibility that divulgers of the Decoding the Disciplines methodology share is precisely what is to be avoided, that is, reinforcing the inequality that generates social injustice. Legitimising the division into talented and not talented does nothing but increase the disparity, by leaving behind those who do not succeed in the task assigned. Thus, one must ask oneself what is necessary to assure that students follow a course of study with success. One must ask oneself what can be offered by way of materials, documents, means and ways of reasoning, so that what we set as the objective of the course may be reached by any student.

The benefit of the methodology is more forceful, first of all, in its extension into programmes within the University, so as to involve teachers of the various disciplines, as well as in its international popularisation at the beginning of the third millennium, and becomes a formative teaching and learning platform.

As we know, there are lessons, in which teachers are quite committed to communicating the importance and relevance of their discipline, while there are students who truly wish to 
follow and understand the lessons, but cannot manage to grasp the meaning of the teacher's words, the sense of which they do not understand (Pace, 2017, pp. 1-4). There are students who actually have no idea what they might do to acquire the mastery required by the teacher and sometimes steer in another direction. Resentment by both parties is created and, if teachers feel their efforts are wasted, students prefer investing their energy elsewhere. The spiral of separation intensifies and remedying the descent becomes increasingly more complicated; it follows that the formal system of education confirms its selective model.

\section{Conclusions}

The finding of partial failure of our university curricula to fully reply to the development needs of young people leads to at least two broad final considerations (Chistolini, 2017a and 2017b). The first consideration concerns the theoretical view of the starting thought and the second consideration concerns the search for the most accredited methodology for developing whatever is necessary.

The commitment to meet the European target on the prevention and overcoming of school leaving, including university, forms part of the viewpoint of allowing every person to participate in full knowledge, by means of any available tools, without excluding procedures that are the domain of the youth, like social networks, and permanently accepting the challenge of the innovation in the acquisition and communication of information. The triad of Comenius, omnes, omnia, omnino, that is, that everyone studies everything in-depth, constitutes the objective of pedagogy and the disciplines, both humanistic and scientific, that are meant to arrive at the destination, even when the roads to be taken appear more impervious, in order to guide and accompany man in the conquest of his most complete humanity, in wisdom, conscience and freedom.

The methodology for Decoding the Disciplines has allowed for activating a highly interactive process through the use of all available means. The definition of the obstacle to learning certainly represents an initial step, which must be immediately followed by putting reasonable replies in place to help students attain success.

\section{References}

Bloom, B. S. (1979). Caratteristiche personali e apprendimento scolastico. Roma: Armando.

Brown, J. S., Collins, A., \& Duguid P. (1989). Situated cognition and the culture of learning. Educational Researcher, 18 (1), 32-42. 
Burggraeve, R. (1997). Emmanuel Levinas et la socialité de l'argent: un philosophe en quête de la réalité journalière: la génèse de Socialité et argent ou l'ambiguïté de l'argent. Leuven: Peeters.

Chistolini, S. (2017a, June 24). Decoding Bottleneck Sandra Chistolini Pedagogy. Retrieved from https://youtu.be/0z2QL-3KJgE.

Chistolini, S. (2017b, June, 24), DDm (Decoding the Disciplines Methodology) Steps 2-3-45 Sandra Chistolini Pedagogy 20/03/17. Retrieved from https://youtu.be/ANjGXk9Fgz4.

Council. Notices from European Union institutions and bodies (2009). Council conclusions of 12 May 2009 on a strategic framework for European cooperation in education and training ('ET 2020') (2009/C 119/02). Official Journal of the European Union, C 119/2.

De Simone, D. (2001). Per un'economia dal volto umano: contro $i$ poteri, le guerre, $i$ profitti. Roma: Malatempora.

European Commission. (2015). Education and Training Monitor 2015. Italy. Luxembourg: Publications Office of the European Union.

Levinas, E. (1985). Umanesimo dell'altro uomo. Genova: Il melangolo.

Middendorf, J., \& Pace, D. (Eds) (2004). Decoding the Disciplines: A model for helping students learn disciplinary ways of thinking. San Francisco: Jossey-Bass.

Pace, D. (2017). The Decoding the Disciplines Paradigm: Seven Steps to Increased Student Learning. Bloomington, Indiana: Indiana University Press.

Scuola di Barbiana (1967). Lettera a una professoressa. Firenze: Libreria editrice fiorentina.

Sen, A. (2011). La ricchezza della ragione. Denaro, valori, identità. Bologna: Il mulino.

Shulman, L. (1987). Knowledge and teaching : foundation of the New Reform. Harvard Education Review, 57(1), 1-22.

The ARWU International Advisory Board (2017, June 16). Academic Ranking of World Universities 2016. Shanghai Ranking Consultancy. Retrieved from http://www.shanghairanking.com/ARWU2016.html

The Times Higher Education World University Rankings (2017, June 16). Young University Rankings 2017. Retrieved from https://www.timeshighereducation.com/world-unirsity-rankings/2017/

Tobias, S. (1992). Disciplinary cultures and general education: what can we learn from our learners?. Teaching Excellence, 4 (6), 1-3.

Unità Organizzativa della Comunicazione e Qualità del PON Ricerca e Competitività 20072013 (a cura di) (2010). Strategia Europa 2020 e politica di coesione. Roma: Arti Grafiche Agostini.

Zamagni, S. (2012). Per un'economia a misura di persona. Roma: Città Nuova. 